\title{
FEM Study of the Effects of Geometric Changes on the Variable Reluctance Shaded-Pole Motors Performance
}

\author{
A. DALCALI and M. AKBABA
}

\begin{abstract}
Due to their robustness, operation from a single phase supply and low cost the shaded pole induction motors (SPIM) are widely used in very low power industrial applications and household appliances. Despite all these advantages the nature of their design alleviates some complicated problems in their analysis and limits the efforts devoted to their performance improvement. In this investigation using Finite Elements Method (FEM) an electromagnetic model of a variable air-gap reluctance SPM motor is built and the effect of geometrical variations of the stator and rotor structures on the performance improvement has been studied. To this end the rotor has been designed as single cage and double cage with different geometries and different types of materials. In addition, the stator is arranged with bridge or without bridge and also with the different inter-pole gap in the bridgeless motor. Finally effect of all these geometrical variations on the motor performance have been studied comparatively.
\end{abstract}

Keywords - Double cage, Finite element method, Shaded pole motor, Stator and rotor structure.

\section{INTRODUCTION}

SPIMs are widely preferred electric motors in small power applications because they are structurally durable, cheap and feed from a single-phase network. Although SPIMs are easy to produce, they are the most difficult machines to analyze theoretically. Since the magnetic field formed in the SPIM is an elliptical rotating magnetic field, the analysis of the machine is difficult. There is no generally accepted method of modeling such motors for their performance analysis. For this reason, a small number of studies have been conducted on such motors [1]-[4].

When studies in the literature are examined, Pessina and Morra found that the component of the magnetic field rotating in the opposite direction of the double short circuit ring motor is less and therefore the vibrations in the torque characteristic are reduced [5]. Makowski obtained the electromagnetic torque value and performance characteristic by considering the saturation and skewing of the rotor bars [6]. Zhou and Rajanathan conducted studies on the optimization of starting torque using 2D finite element analysis. They found that the factors affecting the starting torque were rotor-slot-shape and stator-pole-shape [7]. Sarac et al. chose a commercially available motor model as a reference model and developed two

Manuscript received Feb. 24, 2017

A. DALCALI is with Department of Electrical-Electronics Engineering, Karabuk University, Karabük, 78050, Turkey (ademdalcali@ karabuk.edu.tr)

M. AKBABA is with the Department of Computer Engineering, Karabuk University, Karabük, 78050 Turkey (mehmetakbaba@karabuk.edu.tr). models with maximum efficiency and electromagnetic torque. Because of the limit of the same cross section of the stator and rotor cores in operation, stator winding and parameters were taken into consideration in optimization studies. In addition, the fact that SPIM has elliptical rotating field and high space harmonics increased the difficulty of analyzing the motor. In another study, Sarac reduced the motor losses and increased the efficiency value by using soft magnetic material in the motor core. In addition, by using GA optimization, Sarac reduced the current density in the stator main winding, increased the diameter of the conductor, allowing lower resistance, and thus increased output power [9].

In this study, the effect of the stator and rotor structure of the variable reluctance SPIM has been examined. For this purpose, the motor stator is designed as bridged and bridgeless. Magneto static and transient analysis were carried out by determining the effect of inter-pole gap value of the bridgeless stator structure that is varied from $1 \mathrm{~mm}$ to $9 \mathrm{~mm}$ with a step of $1 \mathrm{~mm}$. With these analyses, the air gap flux distribution, magnetic flux densities, torque curves and power losses of the motor have been obtained. In the rotor part, the effect of the single cage and double cage rotor structure and the performance of the rotor bars in the case of aluminum and copper have been obtained by FEM analysis.

\section{MODELING OF SPIM FOR FEM}

The design and analysis of electric machines involve the resolution of complex and interconnected problems. It is possible to construct the desired design and behavior model of the machine using approximation methods such as finite difference and finite element methods used in the analysis of electric machines [10], [11]. The 2D model of the machine model is created by using electromagnetic analysis, and the analysis of the finite elements is performed. The use of FEM provides designers with time and economic benefits. The application of FEM to machine design ensures that critical design parameters such as core losses, winding inductances and induced torque of the machine are determined with very high accuracy [12]-[14]. The initial models of SPIM and rotor slot measurements are given in the Figure 1. 


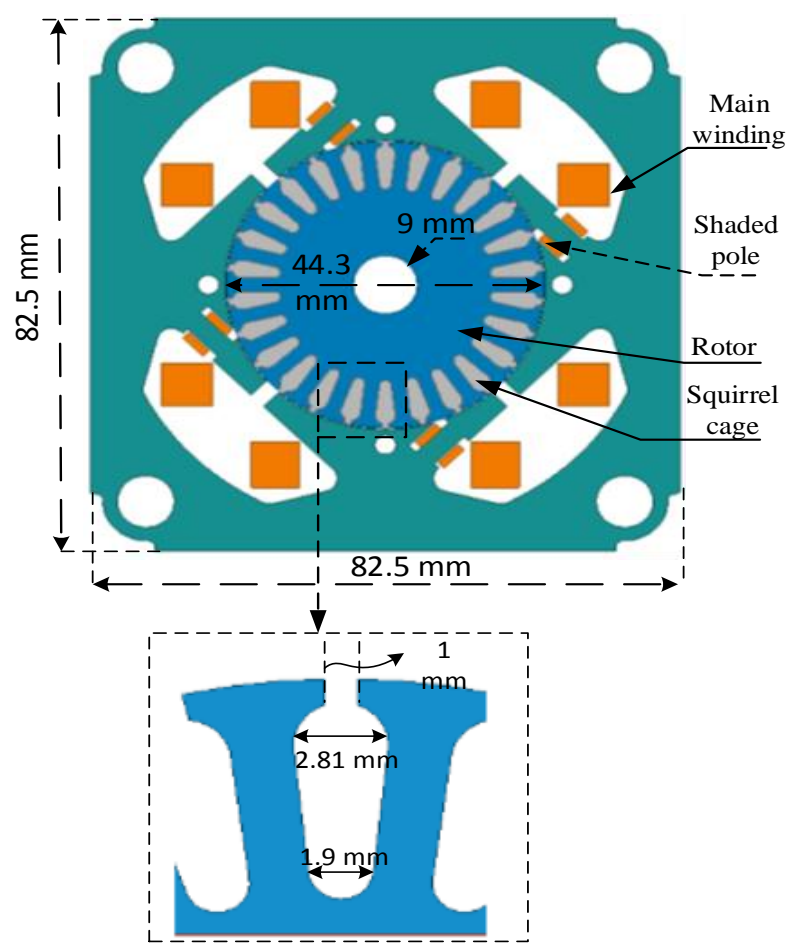

Fig. 1. Initial design of SPIM

The mesh structure of the modeled SPIM is given in the Figure 2. The number of elements is higher near the air gap of the motor and in the rotor slot tips than in the other places since the solution must be made more precise.

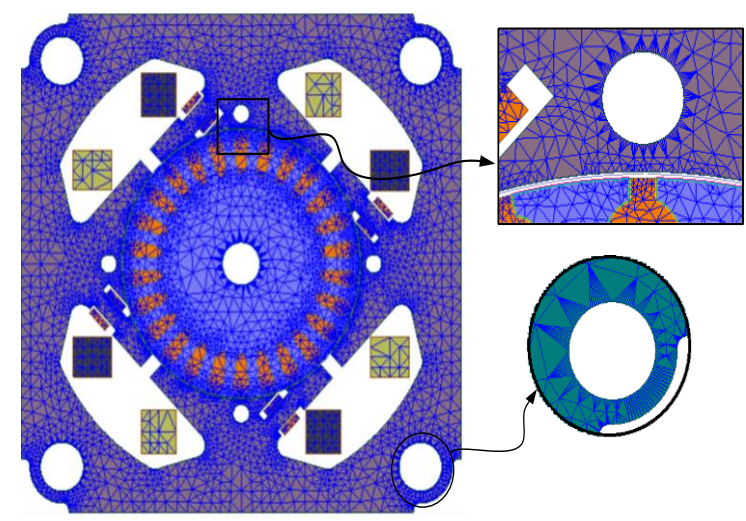

Fig. 2. Mesh structure.

The magnetic field in electric machines is expressed by Maxwell's equations;

$$
\begin{aligned}
& \nabla \times \vec{H}=\vec{J} \\
& \nabla \times \vec{E}=-\frac{\partial B}{\partial t}
\end{aligned}
$$

In Equation (1), $\vec{H}$ is the magnetic field strength $(\mathrm{A} / \mathrm{m}), \vec{J}$ is the current density $\left(\mathrm{A} / \mathrm{m}^{2}\right), \vec{E}$ is the electric field strength $(\mathrm{V} / \mathrm{m})$ and $\vec{B}$ is the magnetic flux density $\left(\mathrm{Wb} / \mathrm{m}^{2}\right)$. The magnetic flux density in terms of magnetic vector potential is expressed as in Equation (2) given below;

$$
\vec{B}=\nabla \times \vec{A}
$$

Relation between the magnetic vector potential and current density is expressed as given in Equation (3);

$$
\nabla \times(v \nabla \times \vec{A})=\vec{J}
$$

Here, $\quad v$ indicates variable permeability as $B=f(H)$ characteristic of the core material is a nonlinear relation and permeability is expressed as $v=\frac{\partial B}{\partial H}$. The magnetic flux density distribution in the motor designed at first attempt is given in Figure 3.

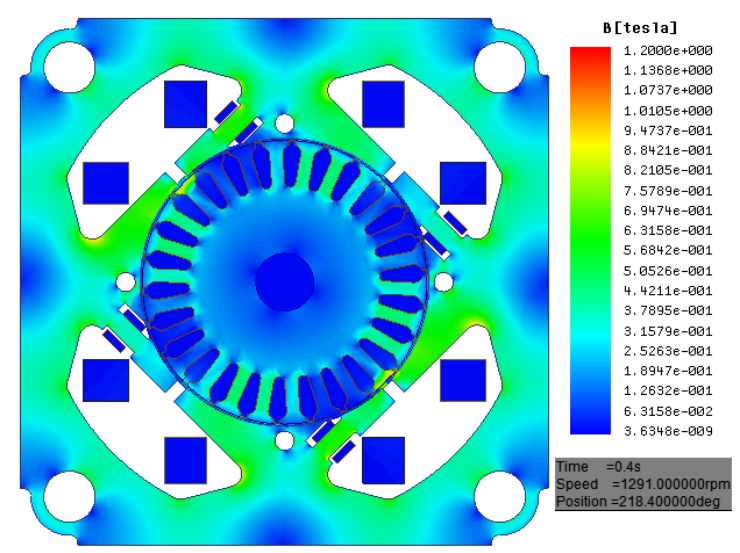

Fig. 3. Magnetic flux density distribution

The distribution of the flux density obtained in Figure 3 is obtained by the following Equations (4) and (5) [4], [15], [16]

$\frac{\partial}{\partial x}\left(v \frac{\partial A}{\partial x}\right)+\frac{\partial}{\partial y}\left(v \frac{\partial A}{\partial y}\right)=-\vec{J}$

Magnetic flux density value is calculated by Equation (5) in 2D analyses.

$$
B=\sqrt{B_{x}^{2}+B_{y}^{2}}
$$

$B_{x}$ shows the component in $\mathrm{x}$-axis direction of magnetic flux density and $B_{y}$ shows the component in $\mathrm{y}$-axis direction of magnetic flux density.

\section{The Stator AND Rotor Structures Under StUdy}

The performance of electric machines is influenced by many physical parameters of the machine. In asynchronous machines the stator and rotor slot numbers and structure change the magnetic circuit of the machine, affecting their electrical performance [17]. 


\section{A. Stator Structure with Bridge and Without Bridge}

The shaded-pole motors are designed as bridged and their performance is explored in some studies conducted during past years [18]. However, the performance of this structure has not been compared with the performance of the traditional bridgeless structure in detail. For this reason, in this part of the study, the bridged and bridgeless structures in the stator section of the SPIM have been examined. In bridgeless structure the amount of the inter-pole gap was varied in the range $0 \mathrm{~mm} \leq x \leq 9 \mathrm{~mm}$ and the analysis were performed with a precision of $1 \mathrm{~mm} .0 \mathrm{~mm}$ here expresses the bridged structure.

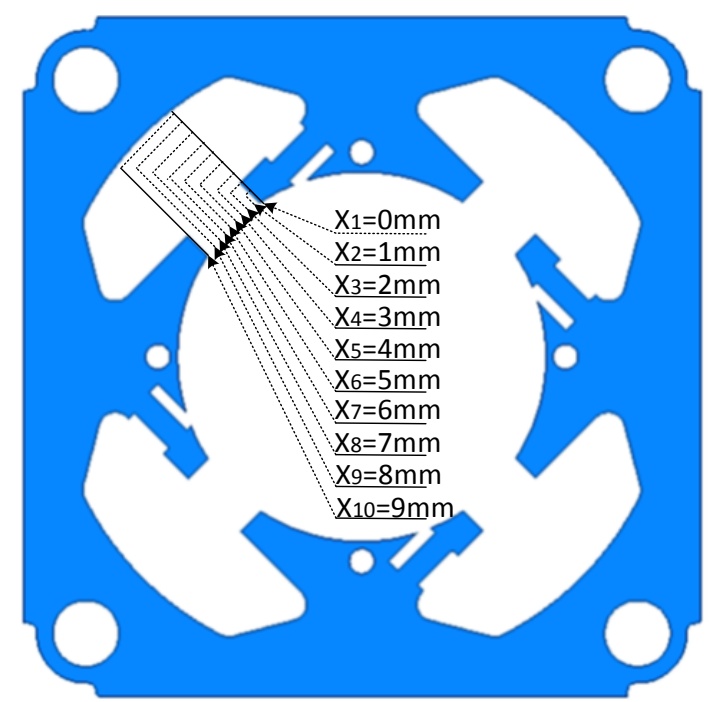

Fig. 4. Variation of the inter-pole gap

\section{B. Single Cage and Double Cage Rotor Structure}

The effects of different slot structures of SPIM on motor performance have not been adequately examined in the literature. In this study the effects of different rotor slot geometries on the motor performance have been examined to some details. For this purpose, SPIM's squirrel cage rotor is designed in two types as single and double cage with two different slot shapes. Another important design parameter of SPIM is the use of aluminum or copper type squirrel cage. The use of copper is disadvantageous in terms of cost and production [19]. Figure 5 shows the designed rotor and squirrel cage structures.

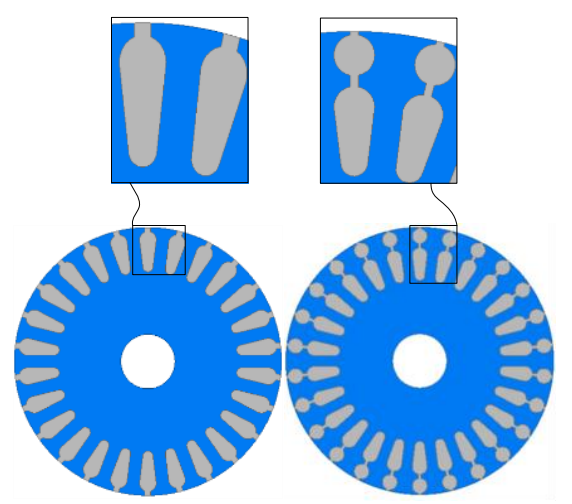

Fig. 5. Single and double cage structures.

\section{Results of ANALYsis}

In the analysis, the inter-pole gap value in the stator was defined as $\mathrm{x}$ and was varied with $1 \mathrm{~mm}$ precision between 0 $\mathrm{mm}$ (bridgeless) and $9 \mathrm{~mm}$. In the rotor part, rotor slots and squirrel cage are designed as single cage and double cage. At the same time, analyses were carried out using copper and aluminum as squirrel cage material. As a result of the conducted study the resulting variation in the efficiency versus the amount of inter-pole gap is given in Figure 6.

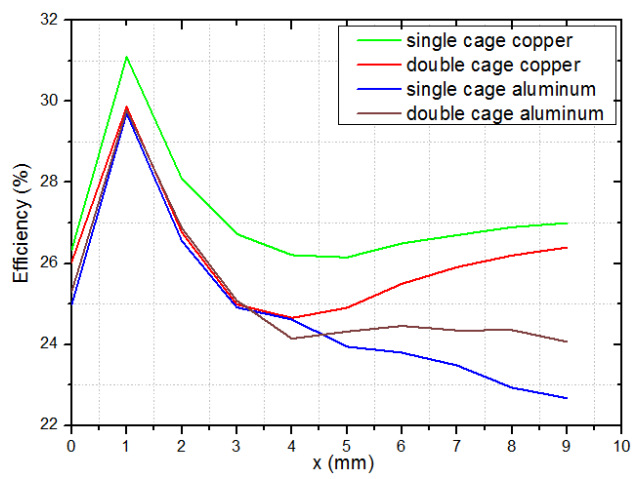

Fig. 6. Variation of efficiency versus amount of inter-pole gap

As expected, rotors with aluminum cage motors have higher rotor resistance than copper ones. Hence, their rotor copper losses are higher and this leads to lower efficiency. The variation of the average value of the air-gap flux density obtained on the contour drawn in the air-gap is given in Figure 7.

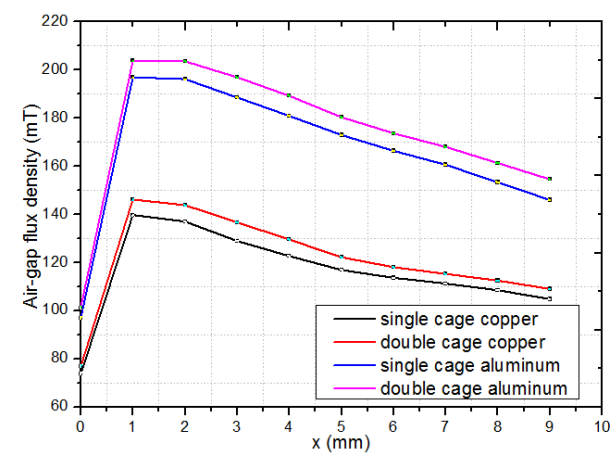

Fig. 7. Variation of of air gap flux density versus amount of inter-pole gap

The amount of flux obtained on the contour was minimal since most of the flux completes its cycle over the stator, and less flux passes to the rotor in a structure with a bridged stator $(x=0)$. The variation of the induced electromagnetic torque versus the amount of inter-pole gap, for a constant slip value of 0.14 is given in Figure 8 . 


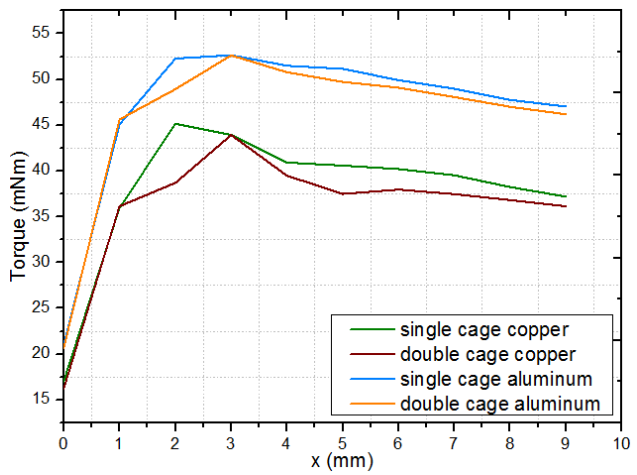

Fig. 8. Variation in torque versus inter-pole gap $(\mathrm{Slip}=0.14)$

When the results are examined, it is seen that both the torque value and the efficiency value are lower in the motors with bridged stator structure than the bridgeless ones. The highest efficiency value $(31.1 \%)$ was obtained with a single cage copper rotor motor at an inter-pole gap value of $1 \mathrm{~mm}$. The highest torque value was obtained with a single cage aluminum rotor motor at an inter-pole gap value of $3 \mathrm{~mm}$.

\section{CONCLUSION}

In this study, the effect of stator and rotor structure of SPIM with variable reluctance on the motor performance was examined. For this purpose, the stator is designed in bridged and bridgeless structures. The amount of inter-pole gap is expressed in terms of variable $\mathrm{x}$ and its effect on the motor performance was examined by varying $\mathrm{x}$ between $0 \mathrm{~mm}$ and 9 $\mathrm{mm}$ with a $1 \mathrm{~mm}$ precision. In addition, the rotor structure is designed as single cage and double cage structures. Copper and aluminum materials with different conductivity values were used as squirrel cage material. The air-gap flux density, torque value, power loss and efficiency values of the motor were obtained by 2D Finite Element analysis. The results of the analysis have shown that the motor with single cage copper rotator has a higher efficiency than the other motor structures at each $\mathrm{x}$ value of the bridgeless stators and bridged stator. When it was evaluated in terms of torque, more torque is obtained in motors with aluminum squirrel cage rotors than in copper rotor motors. The amount of air-gap flux density transferred to the rotor is less than other structures because most of the flux in the bridged type structure completes its cycle over the bridge and stator core instead of going through the rotor. As a result, the torque value induced in the bridged type motors is lower.

\section{REFERENCES}

[1] A. B. Dehkordi, "A Single-Phase Induction Machine Model for RealTime Digital Simulation", presented at the International Conference On Power Systems Transients, Croatia, 2015.
[2] V. Sarac, and G. Stefanov, "Calculation of Electromagnetic Fields in Electrical Machines using Finite Elements Method", International Journal of Engineering and Industries, vol. 2, no. 1, pp. 21-29, 2011.

[3] F. I. Kentli, "A Survey on Design Optimization Studies of Induction Motors During the Last Decade", Journal of Electrical \& Electronics Engineering Istanbul University, vol. 9, no. 2, pp. 969-975, 2009.

[4] A. Dalcal1, and M. Akbaba, "Comparison of 2D and 3D magnetic field analysis of single-phase shaded pole induction motors", Engineering Science and Technology, An International Journal, vol. 19, no. 1, pp. 1-7, 2016.

[5] G. Pessina, and E. Morra, "Optimization and design of the shaded pole single phase asynchronous motor", Proceedings of the International Symposium on Power Electronics, Electrical Drives, Automation and Motion, pp. 469-473, 2012.

[6] K. Makowski, "Determination of performance characteristics of a single-phase shaded pole induction motor by circuit-field method", Electrical Engineering-Springer, vol. 84, no. 5, pp. 281-286, 2002.

[7] D. Zhou, C. B. Rajanathan, and A. T. Sapeluk, "Finite-Element-Aided Design Optimization of a Shaded-Pole Induction Motor for Maximum Starting Torque", IEEE Transactions on Magnetics, vol. 36, no. 5, pp. 3551-3554, 2000

[8] V. Sarac, L. Petkovska, M. Cundev, and G. Cvetkovski, "Comparison between two target functions for optimization of single phase shaded-pole motor using method of genetic algorithms", Journal of Materials Processing Technology, vol. 161, no. 1-2, pp. 89-95, 2005.

[9] V. Sarac, and L. Petkovska, "Application of Soft Magnetic Materials in Development of New Experimental Model of Single Phase Shaded Pole Motor", Proceedings of the Macedonian-Polish Symposium on Applied Electromagnetics, pp. 39-40, 2006.

[10] L. Ho, and W. N. Fu, "Review and Future Application of Finite Element Methods in Induction Motors", Electric Machines \& Power Systems, vol. 26, no. 2, pp. 111-125, 1998.

[11] D. Uygun, "Design and application of 5-phase bipolar excited 10/8 switched reluctance motor with U-type segmental rotor pairs ", Ph. D. thesis, Dept. Electrical Edu. Gazi Uni., Ankara, Turkey, 2012.

[12] C. Ocak, "Design, analysis and application of a new three level brushless dc motor for electric vehicles", Ph. D. thesis, Dept. Electrical Edu. Gazi Uni., Ankara, Turkey, 2013.

[13] S. U. Zhang, "Coupled Magneto-elestostatic Analysis Using Implicit Boundary Finite Element Method", Ph. D. thesis, University of Florida, 2010.

[14] M. Akbaba, and S. Q. Fakhro, “An Improved Computational Technique of the Inductance Parameters of the Reluctance Augmented Shaded-pole Motors Using Finite Element Method", IEEE Transactions on Energy Conversion, vol. 7, no. 2, pp. 308-314, 1992.

[15] A. Dadpour, and K. Ansari, "Conversion of Shaded-Pole Induction Motor to Switched Reluctance Motor and Effects of Pole Shoe and Notch on SRM Noise", Proceedings of the IEEE XXXIII International Scientific Conference Electronics and Nanotechnology, pp. 344-348, 2013.

[16] V. Kindl, K. Hruska, R. Pechanek, J. Sobra, and B. Skala, "The effect of space harmonic components in the air gap magnetic flux density on torque characteristic of a squirrel-cage induction machine", Proceedings of the 17th European Conference on Power Electronics and Applications (EPE'15 ECCE-Europe), pp. 1-5, 2015.

[17] G. Lee, S. Min, and J. P. Hong, "Optimal Shape Design of Rotor Slot in Squirrel-Cage Induction Motor Considering Torque Characteristics", IEEE Transactions on Magnetics, vol.49, no.5, pp. 2197-2200, 2013.

[18] V. Sarac, and T. A. Pacemska, "Simulation Model for Prediction of Transient Performance Characteristics of Single-Phase Shaded Pole Motor", Journal of Electrical Engineering, vol. 67, no. 4, pp. 253-260, 2016.

[19] E. F. Brush, J. G. Cowie, D.T. Peters, and D. J. Van Son, Die-cast Copper Motor Rotors: Motor Test Results, Copper Compared to Aluminum, Energy Efficiency in Motor Driven Systems, Springer, 2003, pp. 136-143. 